\title{
Kinerja Koperasi Peternak Sapi Bandung Utara Lembang, Jawa Barat
}

\author{
Performance Analysis of Cattle Ranchers cooperative \\ in Lembang, North Bandung, West Java
}

Hendrick Tio P. Tambunan ${ }^{1 *}$, Nora H. Pandjaitan ${ }^{2}$ dan Suryahadi ${ }^{3}$

\author{
${ }^{1}$ Program Magister Industri Kecil Menengah,Sekolah Pascasarjana Institut Pertanian Bogor \\ ${ }^{2}$ Departemen Teknik Sipil dan Lingkungan, Fakultas Teknologi Pertanian, Institut Pertanian Bogor \\ Jl. Kamper, Kampus IPB Darmaga, Bogor 16680 \\ ${ }^{3}$ Departemen Ilmu Nutrisi dan Teknologi Pakan, Fakultas Peternakan, Institut Pertanian Bogor \\ Jl. Agatis, Kampus IPB Darmaga, Bogor 16680
}

\begin{abstract}
ABSTRAK
Pertumbuhan koperasi saat ini mengalami perkembangan sangat pesat, ditunjukkan dengan banyaknya ragam usaha koperasi di berbagai daerah di Indonesia, khususnya di Jawa Barat. Kebutuhan susu yang terus meningkat, ditambah produksi susu yang belum memenuhi kebutuhan masyarakat di Jawa Barat membuat para peternak sapi dituntut untuk meningkatkan hasil produksi susu. Salah satu koperasi yang bergerak di bidang ini adalah Koperasi Peternak Sapi Bandung Utara (KPSBU). Tujuan kajian ini adalah (1) menganalisis dan mengevaluasi kinerja manajemen KPSBU Jawa Barat, (2) menganalisis tingkat likuiditas, solvabilitas, dan profitabilitas KPSBU Jawa Barat, (3) menyusun strategi pengembangan usaha KPSBU Jawa Barat. Kajian ini menggunakan pendekatan survei deskriptif, dengan menggunakan data primer dan sekunder, serta metode analisis rasio likuiditas, solvabilitas dan profitabilitas. Strategi pengembangan usaha disusun berdasarkan hasil analisis dari metode strengths, weaknesses, opportunities and threats (SWOT) dan Quantitative Strategic Planning Matrix (QSPM). Berdasarkan analisis QSPM, KPSBU mempunyai beberapa kekuatan, kelemahan, peluang dan ancaman. Kekuatan yang paling besar yang dimiliki KPSBU adalah mutu produk susu segar dan kelemahan yang utama adalah pemasaran produk kurang maksimal, sedangkan faktor yang mempengaruhi peluang yang paling besar adalah kerjasama dengan perusahaan lokal maupun internasional dan ancaman yang terbesar adalah cuaca buruk yang menghambat produksi dan kualitas susu. Untuk itu, Koperasi Peternak Sapi Bandung Utara perlu melakukan perbaikan pada faktor internalnya. Hal ini juga diperkuat dari nilai rasio keuangan likuiditas, solvabilitas, maupun profitabilitas yang menunjukkan bahwa perusahaan belum mampu untuk membayar hutang jangka panjang maupun jangka pendeknya sekaligus untuk menghasilkan laba. Dengan demikian, Koperasi Peternak Sapi Bandung Utara harus berupaya untuk memperbaiki atribut mutu pelayanan dan berupaya agar tingkat kepuasan pelanggannya dapat terus meningkat.
\end{abstract}

Kata kunci: kinerja, koperasi, peternak sapi

\section{ABSTRACT}

At this moment, cooperative growth has experienced a very rapid development, which can be seen from the increasing number of diverse cooperative effort in Indonesia, especially in West Java. The everincreasing needs of milk, added by milk production that has not met the needs of people in West Java makes a fierce competition among Cattle Ranchers Cooperative to produce milk. One of Cooperatives runs in this field is Cattle Ranchers Cooperative of North Bandung. The purpose of this study is (1) to analyze and evaluate management performance of KPSBU in West Java, (2) to analyze the level of liquidity, solvency, and profitability of KPSBU in West Java, (3) to develop business development strategy of KPSBU in West Java. The study used a descriptive survey approach, using primary and secondary data, as well as ratio analysis techniques (1) liquidity, (2) solvency, (3) profitability. Business

\footnotetext{
*) Korespondensi:

Komplek TVRI blok E3/3, Jakarta Timur; e-mail: hendrick_tio0811@yahoo.com
} 
development strategy will be prepared based on the analysis of the SWOT method and QSPM. Based on the analysis QSPM KPSBU has several strengths, weaknesses, opportunities, and threats. The most powerful force possessed KPSBU is quality fresh dairy products and its main drawback is the marketing of products less than the maximum, while the factors that affect the greatest opportunity is cooperation with local and international companies and the biggest threat is the bad weather which disrupted production and milk quality. Therefore, Cattle Ranchers Cooperative of North Bandung needs to make improvements on internal factors. It also reinforced by the value of the financial ratios of liquidity, solvency, and profitability that indicates that the company does not have a good value to pay a long-term and short-term debt as well as to generate profits in the company. Thus, Cattle Ranchers Cooperative of North Bandung must continue to strive to maintain and repair the service quality attribute and keeping customer satisfaction levels continue to rise.

Key words: cattle ranchers, cooperative, performance

\section{PENDAHULUAN}

Usaha persusuan sudah sejak lama dikembangkan di Indonesia. Seiring dengan perkembangan waktu, perkembangan persusuan di Indonesia dibagi menjadi tiga tahap, yaitu Tahap I (periode sebelum 1980) disebut fase perkembangan sapi perah, Tahap II (periode 19801997) disebut fase peningkatan populasi sapi perah, dan Tahap III (periode 1997 sampai sekarang) disebut periode stagnasi. Pada tahap I, perkembangan peternakan sapi perah dirasakan masih cukup lambat karena usaha ini masih bersifat sampingan oleh para peternak. Pada tahap II pemerintah melakukan impor sapi perah secara besar-besaran pada awal tahun 1980-an. Tujuan dilakukan impor ini adalah untuk merangsang peternak untuk lebih meningkatkan produksi susunya. Untuk tahap III, perkembangan sapi perah mengalami penurunan dan stagnasi. Hal tersebut dipengaruhi oleh kejadian krisis ekonomi yang melanda Indonesia. Di samping itu, pemerintah mencabut perlindungan terhadap peternak rakyat dengan menghapus kebijakan rasio susu impor dan susu lokal terhadap IPS (Inpres No.4/1998). Kebijakan ini sebagai dampak adanya kebijakan global menuju perdagangan bebas barrier. Berdasarkan dengan kebijakan tersebut, maka peternak harus mampu bersaing dengan produk susu dari luar negeri, baik dari segi kuantitas maupun kualitas.

Dalam periode 5 tahun terakhir, diperoleh gambaran hasil penjualan susu sapi. Penjualan susu oleh KPSBU berfluktuasi dari tahun ke tahun. Penyebab terjadinya produksi susu yang kurang memenuhi kebutuhan masyarakat adalah menurunnya sapi perah yang dimiliki KPSBU seperti yang terlihat pada Tabel 1. Penurunan tingkat produktivitas susu KPSBU Jawa Barat dan koperasi lainnya secara nasional di satu pihak, tidak berbanding lurus dengan besarnya permintaan pasar (demand) susu nasional. Industri susu segar lokal baru mampu memenuhi pasokan 25\% susu nasional. Oleh karena itu sekitar $75 \%$ dari kebutuhan susu Indonesia masih dipasok dari impor. Pada tahun 2012 total impor susu Indonesia mencapai 205.236 ton dengan nilai USD 705.26 juta (Wiji, 2013).

Tabel 1. Populasi Sapi KPSBU Jawa Barat

\begin{tabular}{lccc}
\hline \multicolumn{1}{c}{ Populasi } & $\begin{array}{c}\text { Desember } \\
2011\end{array}$ & $\begin{array}{c}\text { Desember } \\
2012\end{array}$ & $\begin{array}{c}\text { Turun } \\
\text { ekor }\end{array}$ \\
\hline Sapi & 21.830 ekor & 17.396 ekor & 4.434 \\
Sapi Laktasi & 13.020 ekor & 10.464 ekor & 2.556 \\
\hline
\end{tabular}

Departemen Pertanian menyatakan hasil sensus ternak total sapi perah di Indonesia hanya sekitar 600.000 ekor. Salah satu penyebab menyusutnya populasi sapi perah di Indonesia, sebagaimana diungkapkan Dinas Peternakan (Disnak) Jawa Barat, hal itu terkendala oleh mahalnya harga pakan, sehingga pemilik sapi perah memilih jalan pintas mengubah sapi perah menjadi sapi pedaging (Dhany, 2013).

Jumlah populasi sapi perah yang hanya sekitar 600.000 ekor tidaklah ideal untuk kebutuhan konsumsi penduduk sekitar 250 juta jiwa. Dengan asumsi tingkat konsumsi susu 11 liter per kapita per tahun, maka kebutuhan sapi perah adalah sekitar 1.800 ekor, yang berarti saat ini masih kekurangan sapi perah sekitar 200\% dari populasi sapi perah saat ini (Dhany, 2013).

Kajian ini bertujuan (1) Menganalisis dan mengevaluasi kinerja manajemen, (2) Menganalisis tingkat likuiditas, solvabilitas dan profitabilitas KPSBU Jabar, (3) Menyusun strategi pengembangan usaha KPSBU Jabar. 


\section{METODOLOGI}

Kegiatan ini dilaksanakan pada Koperasi Peternak Sapi Bandung Utara, Jabar yang terletak di Kompleks Pasar Panorama Lembang, Bandung, Jawa Barat. Pengambilan data dan analisis dilakukan dari bulan Juli sampai Desember 2013.

Untuk keperluan analisis data maka dilakukan pengumpulan data primer dan data sekunder. Pengumpulan data dilakukan melalui wawancara, observasi, dan studi pustaka.

Analisis data yang dipergunakan dalam penilitian ini adalah analisis deskriptif, analisis rasio, analisis SWOT (Strength-Weakness-Opportunities-Threats) Matrix, dan QSPM (Quantitative Strategic planning Matrix). Analisis deskriptif digunakan untuk mengevaluasi keadaan umum perusahaan dan menjelaskan kondisi manajemen. Analisis rasio digunakan untuk menilai kinerja keuangan perusahaan dengan terlebih dahulu melakukan kajian terhadap laporan keuangan berupa laporan neraca dan rugi laba untuk tahun buku 2011 dan 2012. Selanjutnya analisis SWOT dan QSPM digunakan untuk menyusun strategi pengembangan usaha dengan menggabungkan kekuatan dan kelemahan organisasi dengan peluang dan ancaman yang ada.

Rasio Likuiditas dianalisis dengan persamaan 1, sedangkan rasio solvabilitas dianalisis dengan persamaan 2 dan rasio profitabilitas dianalisis dengan persamaan 3 dan persamaan 4 .

\begin{tabular}{|c|c|}
\hline Rasio Likuiditas & Aktiva Lancar \\
\hline & Hutang Lancar \\
\hline Rasio Solvabilitas & Jumlah Aktiva \\
\hline & Jumlah Hutang \\
\hline Return On Assets & SHU \\
\hline$(R O A)$ & Kekayaan Bersih \\
\hline Return On & $\begin{array}{c}\text { Laba sebelum } \\
\text { pajak }\end{array}$ \\
\hline s9u & Modal \\
\hline
\end{tabular}

\section{HASIL DAN PEMBAHASAN}

Penjualan hasil produksi pada tahun 2008 sebesar 40,3 juta lt dan tahun 2009 sebesar 46 juta lt, yang berarti meningkat $12 \%$. Pada tahun 2010 penjualan mencapai 49,6 juta lt yang berarti terjadi peningkatan $10 \%$. Pada tahun 2011 penjualan hanya 43,4 juta lt atau terjadi penurunan $15 \%$, tetapi pada tahun 2012 penjualan susu meningkat kembali menjadi 46 juta lt (KPSBU 2012). Fluktua- si yang terjadi dari tahun ke tahun di KPSBU Lembang, Jawa Barat terjadi karena produksi susu yang dihasilkan oleh KPSBU Lembang, tidak stabil bahkan cenderung menurun. Hal itu terjadi dikarenakan populasi sapi yang menurun dari tahun ke tahun. Populasi sapi pada tahun 2011 mencapai 21.830 ekor dan menurun menjadi 17.396 ekor pada tahun 2012. Penyebab menurunnya populasi sapi tersebut dikarenakan sulitnya mencari hijauan makanan ternak (HMT).

Demikian juga asset yang dikelola KPSBU Jabar saat ini bernilai sekitar Rp43 milyar dan jumlah kekayaan Rp17 milyar. Sisa hasil usaha (SHU) yang diperoleh KPSBU Jabar pada tahun 2012 secara keseluruhan sebesar Rp1,5 milyar. Hal ini berarti terjadi peningkatan SHU 12,7\% dibandingkan SHU pada tahun 2011 Rp1,3 milyar (KPSBU, 2012).

Dalam tiga tahun terakhir volume bisnis KPSBU Jawa Barat mengalami fluktuasi sebagaimana terlihat pada Tabel 2. Pada unit usaha penjualan susu, volume bisnis pada tahun 2011 mengalami penurunan $10 \%$. Salah satu penyebab penurunan pada 2011 adalah harga sapi yang murah, dan sulitnya mencari HMT, sehingga produksi susu menurun. Menurut penelitian Santosa, Setiadi dan Wulandari (2013), jumlah produksi susu memiliki pengaruh yang sangat nyata terhadap pendapatan usaha sapi perah $(\mathrm{P} \leq 0,01)$, dimana setiap peningkatan sebesar $1 \%$ akan menaikkan pendapatan peternak Rp1.561. Pada tahun 2012 pendapatan usaha dari penjualan susu kembali meningkat, yang disebabkan oleh meningkatnya produksi susu.

Berdasarkan data yang terdapat pada KPSBU Jawa Barat, fluktuasi volume bisnis koperasi ini terkait dengan berkurangnya penyetoran susu segar dari anggota koperasi. Pada tahun 2012 terjadi penurunan produksi susu hingga mendekati $30 \%$. Tingkat produktivitas semula yang mencapai 150 ton per hari menurun terus sampai 98,5 ton per hari (KPSBU, 2012). Menurut manajemen KPSBU Jawa Barat penurunan populasi sapi menjadi penyebab anjloknya tingkat produktivitas susu ini. Salah satu catatan penting yang diperoleh dari lapangan adalah harga pokok produksi (HPP) mengalami penurunan sebagaimana terlihat pada Tabel 2. Penurunan drastis HPP disebabkan penjualan dan pembelian mengalami penurunan, sedangkan persediaan awal mengalami peningkatan. Turunnya HPP secara drastis pada unit usaha pengolahan susu menjadi salah satu pemicu adanya penurunan kinerja keuangan koperasi. 
Dari Tabel 2 tampak perkembangan rasio biaya dengan volume bisnis pada tahun 2010 adalah 0,995 atau sekitar 99,5\% yang artinya KPSBU Jawa Barat memiliki margin pendapatan hanya $0,5 \%$. Pendapatan ini sudah mencakup dari pos lain-lain di KPSBU Jawa Barat. Pada tahun 2011 rasio biaya dengan volume bisnis koperasi sebesar 0,997 atau 99,7\%. Dengan kata lain KPSBU hanya mengambil profit margin $0,3 \%$. Begitu pula pada tahun 2012 rasio biaya dengan volume bisnis koperasi mengalami penurunan, yakni 99,6\% (Komariah, 2013). Kondisi seperti ini dapat menjadi salah satu indikasi penurunan kinerja keuangan. Hal ini dalam jangka panjang akan menurunkan daya saing KPSBU. Daya saing ini sangat penting bagi koperasi untuk menghadapi persaingan global, karena KPSBU saat ini termasuk ke dalam lima koperasi besar di Indonesia. Menurut Rusdiana dan Sejati (2009), perluasan skala usaha sapi perah harus dapat diimbangi dengan efektifnya sistem kerja koperasi yang menangani hasil produksi sapi perah.

Tabel 2. Harga pokok produksi per unit usaha

\begin{tabular}{lccc}
\hline \multirow{2}{*}{ Unit Usaha } & \multicolumn{3}{c}{ Tahun (Rp juta) } \\
\cline { 2 - 4 } & 2010 & 2011 & 2012 \\
\hline Produksi Susu & 156,8 & 139,9 & 156,9 \\
Pakan Konsentrat & 43,2 & 44,8 & 43,5 \\
Pengolahan Susu & 16,2 & 18,3 & 1,0 \\
Waserda & 10,5 & 8,7 & 25,5 \\
Pembibitan Sapi & 1,9 & 1,5 & 1,5 \\
Perkreditan & - & - & - \\
\hline Total HPP & $\mathbf{2 2 8 , 6}$ & $\mathbf{2 1 3 , 2}$ & $\mathbf{2 2 8 , 4}$ \\
\hline
\end{tabular}

Rasio keuangan KPSBU Jawa Barat telah dianalisis likuiditas, solvabilitas dan rentabilitas. Tingkat likuiditas (kemampuan KPSBU memenuhi kewajiban finansialnya yang dapat dipenuhi) dianalisis dengan current ratio. Dari Tabel 3 terlihat perkembangan rasio likuiditas KPSBU Jawa Barat tahun 2008-2012 yang berfluktuatif selama 5 tahun terakhir. Namun demikian tingkat likuiditas KPSBU Jawa Barat masih berada di atas $100 \%$ setiap tahunnya, yang berarti KPSBU Jawa Barat mampu untuk menjamin hutang lancar dengan aktiva lancarnya.

Menurut Kashmir (2012) rata-rata current ratio untuk industri adalah dua kali (200\%). Dengan demikian kondisi keuangan KPSBU Jawa Barat selama 5 tahun terakhir tergolong kurang baik jika dibandingkan dengan perusahaan lain karena rasionya berada di bawah rataan industri (Rahmawati, 2013).
Tabel 3. Rasio Likuiditas KPSBU

\begin{tabular}{cccc}
\hline Tahun & $\begin{array}{c}\text { Aktiva lancar } \\
\text { (Rp Miliar) }\end{array}$ & $\begin{array}{c}\text { Hutang lancar } \\
\text { (Rp Miliar) }\end{array}$ & $\begin{array}{c}\text { Rasio } \\
\text { Likuiditas } \\
(\%)\end{array}$ \\
\hline 2008 & 21.847 .551 .071 & 14.726 .304 .213 & 148,36 \\
2009 & 24.174 .541 .145 & 18.363 .474 .551 & 131,64 \\
2010 & 29.701 .241 .210 & 21.151 .579 .730 & 140,42 \\
2011 & 28.269 .506 .596 & 19.038 .063 .753 & 148,49 \\
2012 & 35.087 .849 .768 & 27.568 .078 .764 & 127,28 \\
\hline
\end{tabular}

Rasio solvabilitas yang digunakan yaitu debt to asset ratio (DAR), yaitu rasio yang digunakan untuk mengukur seberapa besar aktiva koperasi dibiayai oleh hutang, atau seberapa besar hutang koperasi berpengaruh terhadap hutang aktiva. Dari Tabel 4 tampak bahwa perkembangan tingkat solvabilitas berfluktuatif selama 5 tahun terakhir. Menurut Kashmir (2012), rataan ratio solvabilitas dengan analisis DAR untuk industri adalah 35\%. Dengan demikian, kondisi solvabilitas KPSBU Jawa Barat tergolong kurang baik karena rataan selama 5 tahun terakhir rata-rata pendanaan koperasi dibiayai lebih dari 50\% hutangnya, bahkan pada tahun 2012 pendanaan koperasi dibiayai sampai $61 \%$ dari hutang. Kondisi ini kurang baik bagi KPSBU Jawa Barat. Apabila koperasi ingin menambah pinjamannya maka perlu meningkatkan ekuitasnya untuk menanggulangi kondisi tersebut.

Tabel 4. Rasio solvabilitas KPSBU

\begin{tabular}{cccc}
\hline Tahun & $\begin{array}{c}\text { Total Aktiva } \\
\text { (Rp Miliar) }\end{array}$ & $\begin{array}{c}\text { Total } \\
\text { Hutang } \\
\text { (Rp Miliar) }\end{array}$ & $\begin{array}{c}\text { Rasio } \\
\text { Solvabilitas } \\
(\%)\end{array}$ \\
\hline 2008 & 34,40 & 18,52 & 54 \\
2009 & 37,62 & 21,33 & 57 \\
2010 & 43,46 & 21,15 & 49 \\
2011 & 43,41 & 26,05 & 60 \\
2012 & 50,61 & 30,88 & 61 \\
\hline
\end{tabular}

Profitability merupakan ukuran yang digunakan untuk mengetahui seberapa besar penghasilan sebelum bunga dan pajak yang dihasilkan dari pemanfaatan total asset usaha dan penjualan (Febryani dan Zulfadin, 2003; Suryanto, 2006). Rasio profitabilitas KPSBU Jawa Barat menurut data keuangan KPSBU dari tahun 20082012 tampak bahwa ROA KPSBU cenderung menurun. Semakin tinggi nilai profitabilitasnya, maka semakin tinggi kemampuan usaha untuk menghasilkan keuntungan (Biji et al., 2007). Pada akhir tahun 2008 ROA mencapai 3,35\% kemudian menjadi 3,25\% (2009), dan terus menurun pada tahun berikutnya (Tabel 5). Apabila mengambil 
contoh ROA 2012 maka dapat diketahui bahwa setiap penggunaan $\mathrm{Rp} 1$ harta hanya menghasilkan Rp0,299 laba usaha (Komariah, 2013).

Sementara itu rumusan untuk rentabilitas yang kedua adalah keuntungan terhadap modal sendiri (Return On Equity/ROE). Berbeda dengan ROA maka ROE KPSBU Jawa Barat cenderung lebih stabil dalam 5 tahun terakhir ini. Kalaupun terjadi fluktuasi hanya dalam digit setelah koma, bahkan untuk ROE tahun 2012 adalah yang tertinggi dalam 5 tahun terakhir ini. ROE digunakan untuk mengukur kemampuan KPSBU Jawa Barat dalam menghasilkan laba bersih (SHU) terhadap modal sendiri (kekayaan bersih). Dari Tabel 6 terlihat bahwa ROE tahun 2008 adalah $7,66 \%$ dan menurun pada tahun berikutnya.

ROE tidak hanya mengukur profitabilitas koperasi namun juga efisiensi koperasi dalam mengelola modal yang dimiliki. ROE yang meningkat dapat diartikan bahwa koperasi mampu menghasilkan SHU yang relatif besar tanpa harus membesarkan modal. Dalam hal KPSBU Jawa Barat menunjukkan bahwa posisi koperasi dalam hal ROE relatif stabil.

Matriks EFAS disusun berdasarkan identifikasi faktor peluang dan tantangan yang dimiliki, key success factors (KSF) dari lingkungan eksternal yang diperoleh (Tabel 7). Hasil dari kuesioner pembobotan dan pemberian rating terhadap faktor internal (kekuatan dan kelemahan) tersebut dilakukan perhitungan untuk menentukan nilai rataannya (Rangkuti, 2005).

Dari total skor nilai faktor strategik eksternal KPSBU memiliki nilai 2,32. Nilai tersebut dibawah rataan 2,5 menunjukkan posisi eksternal belum cukup kuat, yaitu perusahaan belum memiliki kemampuan yang cukup kuat dalam memanfaatkan peluang dan mengantisipasi ancaman eksternal (Rangkuti, 2005).

Tabel 5. Rasio rentabilitas ekonomi (ROA)

\begin{tabular}{cccc}
\hline Tahun & $\begin{array}{c}\text { SHU } \\
\text { (Rp Miliar) }\end{array}$ & $\begin{array}{c}\text { Kekayaan Bersih } \\
\text { (Rp Miliar) }\end{array}$ & $\begin{array}{c}\text { ROA } \\
(\%)\end{array}$ \\
\hline 2008 & 1,2 & 34,4 & 3,53 \\
2009 & 1,2 & 37,6 & 3,25 \\
2010 & 1,3 & 43,5 & 3,02 \\
2011 & 1,3 & 43,4 & 3,04 \\
2012 & 1,5 & 50,6 & 2,99 \\
\hline
\end{tabular}

Tabel 6. Rasio rentabilitas modal sendiri (ROE)

\begin{tabular}{cccc}
\hline Tahun & $\begin{array}{c}\text { Laba sebelum } \\
\text { Pajak } \\
\text { (Rp Miliar) }\end{array}$ & $\begin{array}{c}\text { Modal yang } \\
\text { digunakan } \\
\text { (Rp Miliar) }\end{array}$ & $\begin{array}{c}\text { ROE } \\
(\%)\end{array}$ \\
\hline 2008 & 1,2 & 15,8 & 7,66 \\
2009 & 1,2 & 16,3 & 7,50 \\
2010 & 1,3 & 17,5 & 7,52 \\
2011 & 1,3 & 17,3 & 7,61 \\
2012 & 1,5 & 19,7 & 7,67 \\
\hline
\end{tabular}

Tabel 7. EFAS KPSBU Jawa Barat

\begin{tabular}{|c|c|c|c|c|}
\hline Faktor-faktor strategi eksternal & Bobot & Rating & $\begin{array}{c}\text { Bobot } \mathrm{x} \\
\text { Rating }\end{array}$ & Komentar \\
\hline \multicolumn{5}{|l|}{ Peluang $(\mathrm{O}):$} \\
\hline $\begin{array}{l}\text { 1. Perekonomian global yang memungkinkan } \\
\text { terbukanya pasar internasional terhadap produk } \\
\text { koperasi }\end{array}$ & 0,05 & 4 & 0,20 & \multirow{5}{*}{$\begin{array}{l}\text { Permintaan meningkat, } \\
\text { penjualan meningkat } \\
\text { mengakibatkan perluasan dan } \\
\text { peningkatan volume usaha }\end{array}$} \\
\hline $\begin{array}{l}\text { 2. Konsumsi susu dan kesadaran masyarakat } \\
\text { meningkat }\end{array}$ & 0,04 & 4 & 0,16 & \\
\hline $\begin{array}{l}\text { 3. Masih sedikitnya peternak sapi sehingga } \\
\text { produksinya masih kurang }\end{array}$ & 0,04 & 3 & 0,12 & \\
\hline $\begin{array}{l}\text { 4. Pangsa pasar nasional meningkat yang masih } \\
\text { besar ( } 75 \% \text { belum terisi susu lokal) }\end{array}$ & 0,1 & 3 & 0,3 & \\
\hline $\begin{array}{l}\text { 5. Kerjasama dengan perusahaan/koperasi lokal } \\
\text { dan internasional }\end{array}$ & 0,15 & 4 & 0,45 & \\
\hline \multicolumn{5}{|l|}{ Ancaman $(\mathrm{T}):$} \\
\hline $\begin{array}{l}\text { 1. Lahan hijau semakin berkurang menyebabkan } \\
\text { sulitnya mendapatkan pakan ternak }\end{array}$ & 0,10 & 2 & 0,20 & \multirow{6}{*}{$\begin{array}{l}\text { Kehati-hatian terhadap } \\
\text { pesaing baru, baik dari dalam } \\
\text { maupun luar negeri }\end{array}$} \\
\hline $\begin{array}{l}\text { 2. Pesaing dalam bidang yang sama baik dari } \\
\text { dalam maupun luar negeri sehubungan dengan } \\
\text { era perdagangan bebas }\end{array}$ & 0,10 & 1 & 0,10 & \\
\hline 3. Membanjirnya susu impor (75\% pangsa pasar) & 0,05 & 1 & 0,05 & \\
\hline 4. Tarif harga yang ditetapkan pemerintah & 0,07 & 2 & 0,14 & \\
\hline 5. Cuaca ekstrim yang mempengaruhi kondisi sapi & 0,30 & 2 & 0,60 & \\
\hline TOTAL & 1,00 & & 2,32 & \\
\hline
\end{tabular}


Tabel 8. IFAS KPSBU Jawa Barat

\begin{tabular}{|c|c|c|c|c|}
\hline Faktor-faktor strategi internal & Bobot & Rating & $\begin{array}{l}\text { Bobot X } \\
\text { Rating }\end{array}$ & Komentar \\
\hline $\begin{array}{l}\text { Kekuatan (S): } \\
\text { 1. Mutu produk freshdrink tinggi }\end{array}$ & 0,20 & 3 & 0,6 & $\begin{array}{l}\text { Penjualan dan laba (SHU) } \\
\text { meningkat, perluasan dan }\end{array}$ \\
\hline $\begin{array}{l}\text { 2. Volume penjualan dan laba tumbuh } \\
\text { tinggi }\end{array}$ & 0,15 & 4 & 0,6 & peningkatan volume usaha \\
\hline 3. Sistem pengendalian persediaan baik & 0,1 & 4 & 0,4 & \\
\hline \multicolumn{5}{|l|}{ Kelemahan $(W):$} \\
\hline 1. Pilihan produk kurang bervariasi & 0,03 & 2 & 0,06 & \multirow{4}{*}{$\begin{array}{l}\text { Peningkatan upaya } \\
\text { pemasaran produk terutama } \\
\text { susu olahan }\end{array}$} \\
\hline $\begin{array}{l}\text { 2. Pemasaran produk pengolahan susu } \\
\text { kurang maksimal }\end{array}$ & 0,30 & 2 & 0,60 & \\
\hline $\begin{array}{l}\text { 3. Tingkat pendidikan SDM masih } \\
\text { kurang }\end{array}$ & 0,075 & 2 & 0,15 & \\
\hline 4. Lokasi outlet kurang strategis & 0,02 & 2 & 0,04 & \\
\hline TOTAL & 1,00 & & 3,15 & \\
\hline
\end{tabular}

\begin{tabular}{|c|c|c|}
\hline Faktor Eksternal & $\begin{array}{l}\text { Kekuatan (S) } \\
\text { 1. Mutu produk freshdrink tinggi } \\
\text { 2. Volume penjualan dan laba } \\
\text { tumbuh tinggi } \\
\text { 3. Sistem pengendalian persediaan } \\
\text { baik }\end{array}$ & $\begin{array}{l}\text { Kelemahan (W) } \\
\text { 1. Pilihan produk kurang } \\
\text { bervariasi } \\
\text { 2. Pemasaran produk pengolahan } \\
\text { susu kurang maksimal } \\
\text { 3. Tingkat pendidikan SDM masih } \\
\text { kurang } \\
\text { 4. Lokasi outlet kurang strategik }\end{array}$ \\
\hline $\begin{array}{l}\text { Peluang (O) } \\
\text { 1. Perekonomian global yang } \\
\text { memungkinkan terbukanya pasar } \\
\text { internasional terhadap produk } \\
\text { koperasi } \\
\text { 2. Konsumsi susu dan kesadaran } \\
\text { masyarakat meningkat } \\
\text { 3. Kecenderungan penjualan } \\
\text { meningkat } \\
\text { 4. Pangsa pasar nasional meningkat } \\
\text { yang masih besar ( } 75 \% \text { belum terisi } \\
\text { susu lokal) } \\
\text { 5. Kerjasama dengan perusahaan/ } \\
\text { koperasi lokal dan internasional } \\
\end{array}$ & $\begin{array}{l}\text { 1. Memanfaatkan pangsa pasar yang } \\
\text { masih terbuka sangat luas } \\
\text { 2. Memanfaatkan kekuatan dan } \\
\text { nama besarnya untuk memperoleh } \\
\text { kesempatan dari pemerintah } \\
\text { 3. Memanfaatkan kekuatan } \\
\text { keuangannya untuk } \\
\text { mengkonversikan simpanan } \\
\text { anggota jadi sertifikat modal } \\
\text { koperasi (SMK) } \\
\text { 4. Memanfaatkan kerjasama dengan } \\
\text { para pihak termasuk perusahaan } \\
\text { swasta }\end{array}$ & $\begin{array}{l}\text { 1. Mendapatkan dukungan } \\
\text { pemerintah dalam mengatasi } \\
\text { persoalan pemasaran baik } \\
\text { nasional maupun internasional } \\
\text { 2. Bekerjasama dengan pihak } \\
\text { perguruan tinggi/lembaga- } \\
\text { lembaga lainnya } \\
\text { 3. Memanfaatkan tingkat } \\
\text { kualifikasi sebagai koperasi yang } \\
\text { tergolong besar di Indonesia } \\
\text { untuk memperoleh outlet baru } \\
\text { yang strategik }\end{array}$ \\
\hline $\begin{array}{l}\text { Ancaman (T) } \\
\text { 1. Lahan hijau semakin berkurang } \\
\text { menyebabkan sulitnya } \\
\text { mendapatkan pakan ternak } \\
\text { 2. Pesaing dalam bidang yang sama, } \\
\text { baik dari dalam maupun luar } \\
\text { negeri sehubungan dengan era } \\
\text { perdagangan bebas } \\
\text { 3. Membanjirnya susu impor ( } 75 \% \\
\text { pangsa pasar) } \\
\text { Tarif harga yang ditetapkan } \\
\text { pemerintah } \\
\text { 5. Cuaca ekstrim yang menghambat } \\
\text { kuantitas dan mutu susu }\end{array}$ & $\begin{array}{l}\text { 1. Memanfaatkan kekuatannya untuk } \\
\text { melakukan nego dalam } \\
\text { penyediaan lahan hijau } \\
\text { 2. Memanfaatkan asosiasi untuk } \\
\text { menetapkan tarif harga minimal } \\
\text { susu } \\
\text { 3. Memanfaatkan kemampuan para } \\
\text { pihak untuk mengantisipasi } \\
\text { apabila terjadi cuaca ekstrim } \\
\text { 4. Memanfaatkan para pesaing } \\
\text { menjadi kawan } \\
\text { 5. Bekerjasama dengan pihak } \\
\text { koperasi maupun perusahaan } \\
\text { yang lebih kuat }\end{array}$ & $\begin{array}{l}\text { 1. Meningkatkan kerjasama dengan } \\
\text { koperasi-koperasi susu untuk } \\
\text { memperjuangkan kepentingan } \\
\text { bersama } \\
\text { 2. Memanfaatkan potensi IPS } \\
\text { terutama IPS lima besar agar } \\
\text { bias memikirkan kepentingan } \\
\text { masa depan persusuan } \\
\text { 3. Meningkatkan dukungan data } \\
\text { dan informasi dari instansi } \\
\text { terkait (BOMG, Lapan, dll) }\end{array}$ \\
\hline
\end{tabular}


Tabel 9. Quantitative strategic planning matrix

\begin{tabular}{|c|c|c|c|c|c|c|}
\hline \multirow{3}{*}{ Kode } & \multirow{3}{*}{ Faktor Kunci } & \multirow{3}{*}{$\begin{array}{l}\text { Bobot } \\
\text { (a) }\end{array}$} & \multicolumn{4}{|c|}{ Alternatif Strategi } \\
\hline & & & \multicolumn{2}{|c|}{ Strategi 1} & \multicolumn{2}{|c|}{ Strategi 2} \\
\hline & & & $\begin{array}{l}\text { AS } \\
\text { (b) }\end{array}$ & $\begin{array}{l}\text { TAS } \\
(\mathrm{axb})\end{array}$ & $\begin{array}{l}\text { AS } \\
(\mathrm{c})\end{array}$ & $\begin{array}{l}\text { TAS } \\
(\mathrm{axc})\end{array}$ \\
\hline & Kekuatan $(S):$ & & & & & \\
\hline S1 & - Mutu produk freshdrink tinggi & 0,125 & 4 & 0,500 & 3 & 0,375 \\
\hline S2 & - Volume penjualan dan laba tumbuh tinggi & 0,400 & 4 & 1,600 & 3 & 1,200 \\
\hline \multirow[t]{2}{*}{ S3 } & - Sistem pengendalian persediaan baik & 0,050 & 4 & 0,200 & 3 & 0,150 \\
\hline & Kelemahan $(W)$ : & & & & & \\
\hline W1 & - Pilihan produk kurang bervariasi & 0,030 & 2 & 0,060 & 1 & 0,030 \\
\hline W2 & $\begin{array}{l}\text { - Pemasaran produk pengolahan susu kurang } \\
\text { maksimal }\end{array}$ & 0,300 & 2 & 0,600 & 1 & 0,300 \\
\hline W3 & • Tingkat pendidikan SDM masih kurang & 0,075 & 2 & 0,150 & 1 & 0,075 \\
\hline \multirow[t]{2}{*}{ W4 } & - Lokasi outlet kurang strategis & 0,020 & 2 & 0,040 & 1 & 0,020 \\
\hline & Peluang $(\mathrm{O})$ : & & & & & \\
\hline O1 & $\begin{array}{l}\text { - Perekonomian global yang memungkinkan } \\
\text { terbukanya pasar internasional terhadap produk } \\
\text { koperasi }\end{array}$ & 0,080 & 4 & 0,320 & 3 & 0,240 \\
\hline $\mathrm{O} 2$ & $\begin{array}{l}\text { - Konsumsi susu dan kesadaran masyarakat } \\
\text { meningkat }\end{array}$ & 0,130 & 4 & 0,520 & 3 & 0,390 \\
\hline $\mathrm{O} 3$ & - Kecenderungan penjualan meningkat & 0,030 & 4 & 0,120 & 3 & 0,090 \\
\hline O4 & $\begin{array}{l}\text { - Pangsa pasar nasional meningkat yang masih besar } \\
\text { (75\% belum terisi susu lokal) }\end{array}$ & 0,290 & 4 & 1,160 & 3 & 0,870 \\
\hline O5 & $\begin{array}{l}\text { - Kerjasama dengan perusahaan/koperasi lokal dan } \\
\text { internasional }\end{array}$ & 0,010 & 4 & 0,040 & 3 & 0,030 \\
\hline $\mathrm{T} 1$ & $\begin{array}{l}\text { Ancaman }(\mathrm{T}) \text { : } \\
\text { - Lahan hijau semakin berkurang menyebabkan } \\
\text { sulitnya mendapatkan pakan ternak }\end{array}$ & 0,160 & 2 & 0,320 & 1 & 0,160 \\
\hline $\mathrm{T} 2$ & $\begin{array}{l}\text { - Pesaing dalam bidang yang sama baik dari dalam } \\
\text { maupun luar negeri sehubungan dengan era } \\
\text { perdagangan bebas }\end{array}$ & 0,040 & 2 & 0,080 & 1 & 0,040 \\
\hline T3 & - Membanjirnya susu impor (75\% pangsa pasar) & 0,150 & 2 & 0,300 & 1 & 0,300 \\
\hline $\mathrm{T} 4$ & - Tarif harga yang ditetapkan pemerintah & 0,060 & 2 & 0,120 & 1 & 0,120 \\
\hline $\mathrm{T} 5$ & $\begin{array}{l}\text { - Cuaca ekstrim yang menghambat kuantitas dan } \\
\text { kualitas susu }\end{array}$ & 0,050 & 2 & 0,100 & 1 & 0,050 \\
\hline
\end{tabular}

Matriks IFAS disusun berdasarkan identifikasi faktor kekuatan dan kelemahan yang dimiliki, key success factors (KSF) dari lingkungan internal yang diperoleh dirangkum dalam Tabel 8. Hasil dari kuesioner pembobotan dan pemberian rating terhadap faktor internal (kekuatan dan kelemahan) tersebut dilakukan perhitungan untuk menentukan nilai rataannya (Rangkuti, 2005). Dari total skor nilai faktor-faktor strategik internal KPSBU memiliki nilai 3,15. Nilai tersebut di atas rataan 2,5 yang menunjukkan posisi internal KPSBU memiliki posisi kuat, yaitu perusahaan memiliki kemampuan yang cukup kuat dalam memanfaatkan kekuatan dan mengantisipasi kelemahan internal (Rangkuti, 2005).

Berdasarkan Tabel 9, strategi yang paling menarik diantara strategi yang dihasilkan (secara berurutan) adalah:
1. Strategi 1 dalam hubungannya dengan volume penjualan dan laba yang semakin meningkat (TAS: 1,600$)$

2. Strategi 1 dalam hubungannya dengan pemasaran produk pengolahan susu yang masih kurang maksimal (TAS: 1,200)

3. Strategi 1 dalam hubungannya dengan pangsa pasar nasional meningkat yang masih besar (75\% belum terisi susu lokal) (TAS: 1,160)

4. Strategi 1 dalam hubungannya dengan lahan hijau semakin berkurang, menyebabkan sulitnya mendapat pakan ternak (TAS: 0,640)

5. Strategi 1 dalam hubungannya dengan membanjirnya susu impor (75\% pangsa pasar) (TAS: 0,600)

Kesimpulan dari analisa SWOT sampai QSPM tampak bahwa kelemahan yang paling utama adalah lokasi outlet kurang strategis. Kelemahan ini berdampak pada penjualan dan 
pemasaran yang tidak memuaskan, ditambah ancaman pesaing, baik dari dalam negeri maupun luar negeri yang ikut meramaikan persusuan Indonesia. Hal tersebut merupakan hal paling utama yang menyebabkan kinerja KPSBU belum optimal. strategi terpenting ke KPSBU adalah dari sisi peningkatan produksi. Hal ini terkait dengan peluang bahwa 75\% kebutuhan susu segar di Indonesia masih dipenuhi oleh impor. Dalam rangka meningkatkan produksi itulah terkait dengan penyediaan lahan hijau (MHT) yang dibutuhkan sebagai campuran pokok pakan ternak sapi perah. Dengan tersedianya lahan hijau tersebut, maka penambahan populasi sapi sampai angka yang dibutuhkan dapat diimbangi dengan penyediaan pakan. Namun perlu diingat pula bahwa biaya terbesar dalam biaya produksi adalah rataan biaya pakan konsentrat, pakan hijauan, tenaga kerja serta biaya penyusutan (Halolo et al, 2013). Sama halnya dengan hasil penelitian Sundari dan Katamso (2010) bahwa biaya terbesar dikeluarkan oleh biaya pakan (61,28\%). Dengan meningkatnya produksi susu segar tersebut, maka KPSBU dapat mengisi peluang kekurangan pasokan susu segar tersebut.

\section{KESIMPULAN}

Tingkat produktivitas susu segar yang relatif masih rendah apabila dibandingkan dengan pangsa pasra (market share) nasional yang begitu besar. Dari tujuan penelitian kedua terbukti bahwa tingkat keuntungan (provitabiltas) koperasi cenderung menurun dilihat sejak 5 tahun terakhir (2008), bahkan mencapai, di bawah angka $3 \%$ (tepatnya 2,99) yang berada di bawah rataan keuntungan koperasi pada umumnya.

Untuk strategi pengembangan usaha ke depan, sebagai tujuan ketiga penelitian pekerjaan rumah terbesar KPSBU Jawa Barat adalah mencanangkan peningkatan produktivitas susu segar, memperkuat diversifikasi usaha melalui susu olahan, memperluas pasar, dan mempertimbangkan pola kemitraan antara koperasi dengan usaha swasta sebagaimana telah sukses dilaksanakan di negara lain khususnya di negara New Zealand.

\section{DAFTAR PUSTAKA}

Biji, R., S. R. Kooistra and H. Hogeven. 2007. The Profitability of Automatic Milking on Dutch Dairy Farm. J. Dairy Sci, 90(1): 239-248.
Departemen Koperasi, Dir. Penyuluhan Koperasi. 1998. Pedoman Pelaksanaan Inpres Nomer 4 Tahun 1998, Jakarta.

Dhany, R. 2013. http://finance.detik.com/read/ 2013/06/03/114708/2262960/4/miris-70kebutuhan-susu-di-indonesia-dipasok-dariimpor (3 Juni 2013).

Febriyani, A. dan R. Zulfadin. 2003. Analisis kinerja bank devisa dan bank non devisa di Indonesia. J. Ekonomi dan Keuangan, 7(4): 38-54.

Kasmir. 2012. Analisis Laporan Keuangan, PT Raja Grafindo Persada, Jakarta

Komariah, F. 2013. Analisis Kinerja Keuangan Dalam Rangka Pengembangan Usaha Koperasi Menghadapi Globalisasi (Studi Kasus pada Koperasi Peternak Sapi Bandung Utara). Skripsi pada Program Studi Manajemen Konsentrasi Manajemen Keuangan, Institut Koperasi Indonesia.

KPSBU Jawa Barat. 2012. Laporan Tahunan ke 41. Lembang: KPSBU Jawa Barat.

Haloho, R.D., S.I. Santoso, dan S. Marzuki. 2013. Analisis Profitabilitas pada Usaha Peternakan Sapi Perah di Kabupaten Semarang. Jurnal Pengembangan Humaniora, 13(1): 65-72.

Rahmawati, K. 2013. Alternatif Model Konversi Simpanan Wajib dan setara Simpanan Wajib Menjadi Sertifikat Modal Koperasi (Studi Kasus pada Koperasi Peternak Sapi Bandung Utara, Kabupaten Bandung Barat). Skripsi pada Program Studi Manajemen Konsentrasi Manajemen Keuangan, Institut Koperasi Indonesia (IKOPIN).

Rangkuti, F. 2005. Analisis SWOT Teknik Membedah Kasus Bisnis. Gramedia Pustaka Utama, Jakarta.

Rusdiana, S. dan W.K. Sejati. 2009. Upaya pengembangan agribisnis sapi perah dan peningkatan produksi susu melalui pemberdayaan koperasi susu. Jurnal Agro Ekonomi, 27: 43-51.

Santoso, S.I., A. Setiadi dan R. Wulandari. 2013. Analisis Potensi Pengembangan Usaha Peternakan Sapi Perah dengan Menggunakan Paradigma Agribisnis di Kecamatan Musuk Kabupaten Boyolali. Buletin Peternakan, 37(2): 125-135.

Sundari dan Katamso. 2010. Analisis Pendapatan Peternak Sapi Perah Lokal dan Eks-Impor Anggota Koperasi Warga Mulya di Kabupaten Sleman Yogyakarta". J. Caraka Tani, 24(1): 26-32. 
Suryanto, B. 2006. Profitabilitas Usaha Jagal Sapi di Kabupaten Pati Provinsi Jawa Tengah. J. Indonesian Trop. Anim. Agric.. 31(3): 184188.
Wiji, N. 2013. Produksi Lokal Terus Melorot, RI harus Impor Susu Rp6 Triliun/Tahun. www.detikfinance.com, 21 Februari 2013 (diunduh 2013/10/24). 